\title{
AN ELECTRON MICROSCOPY OF THE RENAL DIFFERENTIATION
}

\author{
II. GLOMERULUS \\ YASUNOSUKE SUZUKI \\ Department of Pathology, School of Medicine \\ Keio University
}

(Received on June 15, 1959)

\section{INTRODUCTION}

The fine structure of the glomerulus has been studied electron microscopically by many investigators and attempts to establish a relationship between the fine structure and the function of the glomerulus are being made and more frequently4) 677)199 20221)22223252529331). In the field of pathology also, many investigators are trying to observe lesions in the glomerulus with the electron microscope ${ }^{526227)}$. In spite of the fact that almost everything is known about the structure of the glomerulus one important point that remains vague to electron microscopists is the existence of the mesangium ${ }^{33)}$.

The author has been able to confirm the existence of the mesangium, which is a point of controversy among investigators, and has made electron microscopic studies of the glomerular differentiation. The author has studied the relationship between the mesangium and other glomerular components (i.e., the epithelial cells, the basement membrane, and the endothelial cells, which existence has been generally recognized) dúring various stages of development.

To date Hall ${ }^{8)}$ and $\mathrm{Kur}^{12)}$ may be mentioned as electron microscopists who have done the same type of study. Both investigators deny the existence of the mesangium, and the author finds a difference of opinion in other minor matters also. The author intends to report in this paper the observations made of the glomerulus at various stages of development, from the earliest stage of glomerulogenesis to maturity, and to discuss the characteristics of the mesangium from the viewpoint of embryological observation

\section{MATERIALS AND METHOD}

As indicated in Table 1 the Wistar strain rats were used...the fetus and rats at various stages of maturity. Weight of the rats and of the right kidney is as 
shown. Generally the left kidney was used for electron microscopy and the right for light microscopy. The kidney was quickly talken out of the body, sliced with a thin razor blade into specimens under $1 \mathrm{~mm}^{3}$ in size, fixed for thirty minutes in one per cent $\mathrm{OsO}_{4}$ buffered at about $\mathrm{pH} 7.2$ with veronal-acetate buffer following Palade's method. After fixation the specimens were washed in water, hydrated and embedded in methacrylate. Porter-Blum's Microtome was used and observation made under a HU-10 Type Electron microscope.

Table 1

\begin{tabular}{rrrr}
\hline No. & & $\begin{array}{c}\text { Weight of rat } \\
(\mathrm{g})\end{array}$ & $\begin{array}{c}\text { Weight of the right kidney } \\
(\mathrm{mg})\end{array}$ \\
\hline 1 & fetus & 2.4 & 11 \\
2 & fetus & 3.5 & 18 \\
3 & fetus & 3.8 & 20 \\
4 & fetus & 4.9 & 28 \\
5 & fetus & 5.0 & 23 \\
6 & fetus & 5.8 & 27 \\
7 & 1 day old newbotn & 5.2 & 37 \\
8 & 3 day " " " & 6.5 & \\
9 & 7 day " " & 11.2 & 76 \\
10 & 14 day " " & 18.5 & 100 \\
11 & 21 day " (immature) & 24.5 & 144 \\
12 & 28 day ", (immature) & 38.0 & 150 \\
13 & 7 months old (mature) & 280.0 & 980 \\
\hline
\end{tabular}

\section{OBSERVATION}

\section{A) Light Microscopy}

Figure 1 is the outermost layer of the renal cortex (Specimen No. 1) and the histological findings of what is accepted today as the earliest stages of the glomerulogenesis can be observed. The metanephrogenic vesicle differentiated from the metanephrogenic tissue (M.T) which has been originated from the mesoderm can be seen. The metanephrogenic vesicle is composed of the ininer and the outer layer, and Bowman's space (B.S) is seen in between. Flattening of the outer layer has already begun. It is generally believed that glomerular capillary appear directly beneath the inner layer (at the vascular pole of the primitive glomerulus) but it is not clear in this photograph. Lewisis' häs presented a figure more or less like Figure $z$ and suggests that the glomerulat anlage is originated from the inner layer of the metanophirogeric vesicle. 
Figure 3 shows an immature glomerulus at a further stage of differentiation. 1) Near the hilum of the glomerulus a mass of cellular elements can be observed. 2) The formation of several blood cavities can be seen immediately beneath the inner layer. 3) At this stage the epithelial cells are still cylindrical and are stained with basophilic. The number of cells existing in the glomerulus is great for its size. 4) The basement membrane is not stained with PAS staining. The glomerulus seen in Figure 3 as compared with a mature glomerulus differ in the points as given above, but structural characteristics are very similar. The various stages of development of the glomerulus as shown in Figure 1 to 3 can be observed within the same renal cortex specimen when taken from an embryo in advanced stage of development and it is generally accepted that glomerulogenesis proceeds from the inner layer towards the outer layer of the cortex. It is said that glomerular formations of rats, unlike that of human beings, can be seen to be active several days after birth, and the author also has observed quite clearly the formation of metanephrogenic vesicle from metanephrogenic tissue in the outer layer of the cortex for three days after birth.

Figure 4 is a mature glomerulus and large numbers of capillary lumen, flattened epithelial cells, the basement membrane which is stained light red with PAS staining, endothelial cells with small cytoplasm, and mesangium stained light red by PAS staining are noted. However the cytoplasm of the mesangial cells does not show up.

\section{B) Electron Microscopy}

\section{a) General Appearance}

Figure 5 shows the glomerlus in its earliest stage of formation as seen under the electron microscope and corresponds to Figure 1 of light microscopy. It is impossible to observe the differentiation process from metanephrogenic tissue to metanephrogenic vesicle through this photograph but the photograph is interesting in observing the early stages of the glomerulogenesis. The outer layer (O.M.V) of the metanephrogenic vesicle has already started flattening at this early stage when glomerular formation has barely started. The transitional portion from the outer layer to the inner layer shows two rows of cells and is very similar in arrangement to the primitive arrangement of the proximal tubule cells seen in the urinary pole. The inner layer cells (I. M. V) are an elongated cylindar in shape and small numbers of little mitochondria can be seen within the cytoplasm. How ever endoplasmic reticulum and golgi complex are small in number and size as yet.

Directly below the inner layer cells erythrocytes and reticulocytes are seen in the intercellular space of the mesenchymal cells. These blood corpuscles are in immediate contact with the cell membrane of the mesenchymal cells (glomerular 
anlage cells). Therefore the space that these blood corpuscles occupy...intercellular space...is thought to be the blood channel forming within the glomerular anlage and the very initial stage of the glomerular capillary. Mesenchymal cells, like the inner layer cells and the outer layer cells, hold a small number of mitochondria and endoplasmic reticulum but have no peculiar characteristics. It is to be noted that at this stage the basement membrane has not yet appeared and therefore it is hard to distinguish some of the inner layer cells from the mesenchymal cells. (Figure 6; part of Figure 5).

Figure 7 is an immature glomerulus where differentiation is a little more advanced than Figure 5. Basement membrane although as yet delicate appears quite conspicuously directly beneath the inner layer cells. The glomerular anlage cells immediately below the inner layer cells has greatly proliferated and just beneath the basement membrane the primitive blood cavity such as is seen in Figure 5 may be noted. In part of the inner layer cells lateral cell membranes have separated from each other and Bowman's space is seen a little more clearly. At the basal portion of the inner layer cells, the cell membranes contacting the basement membrane have started pedicel (Hall) 738 ) differentiation which will be elaborated on later. The inner layer and the basement membrane are already slightly curved as result of the outward pressure from the proliferated glomerular anlage cells and the increase of blood quantity that flows within the blood cavities. The immature glomerulus as seen in Figure 8 shows further active proliferation of the glomerular anlage cells from Figure 7. Both A and B indicate anlage cells surrounded by basement membrane. Though continuity with each other cannot be seen by this photograph, tri-dimentionally, $A$ and $B$ are thought to be connected. The reason why they appear disconnected is because the lumplike proliferation of the anlage cells on the side by Bowman's space has increased prominently. The inner layer cells are round in shape, its lateral cell membranes are further separated from each other and show the first stages of pedicel differentiation.

At this stage the transitional portion between the inner and outer layers, the outer layer and the primitive renal tubule also are covered continuously by the basement membrane, although somewhat vaguely as yet. Thus, glomerular basement membrane has a direct continuity with the basement membrane of the outer layer and the renal tubule.

Figure 9 is an immature glomerulus in further stage of differentiation, and is an electron microscopy approximately corresponding to the light micrograph shown as:Figure 3. At this stage the blood cavities directly beneath the basement membrane have been dilated strikingly because of larger quantities of blood flow. Mesenchymal cells have flattened, and resemble endothelial cells as seen in a mature glomerulus. 
The inner layer and the basement membrane show distinct "ins and outs" and strongly resemble the lobular pattern of a mature glomerulus. A small number of mature pedicels has appeared in the basal portion of the epithelial cells. In spite of maturity of other components a cell mass in the centre portion of the glomeruli still exists and its location is similar to that of the anlage cells as seen in the earlier stages of the glomerular development. From observations of the above photographs concerning the process of the glomerular anlage cell differentiation, the following interesting facts are noted. 1) The differentiation from anlage cells to endothelial cells occurs almost always beneath the basement membrane. 2) The structural components forming the wall of blood cavities that are produced one after the other by the flattening of anlage cells, regardless of the ever complicating appearance of the glomerulus, throughout remain in the order of the inner layer cells (prospective epithelial cells), basement membrane, endothelial cells (differentiated from anlage cells) and anlage cells, from the Bowman's space side.

Therefore, as Yajima ${ }^{32}$ ) has pointed out, the structure of the walls of the blood cavities known as glomerular capillary, differ from that of the ordinary capillary in the following manner; in an ordinary capillary the basement membrane completely surrounds the sheets of endothelial cells, while in the glomerular capillary the basement membrane does not exist between the endothelial cells and the glomerular anlage cells. In other words the structural components of the glomerular capillary walls are arranged unsymmetrically, except when seen from the direction of the Bowman's space towards vascular pole, and in this manner differ from that of ordinary capillary walls.

Figure 10 is a mature glomerulus and A. $a$ is what Yamada ${ }^{31}$, has noted as afferent arteriole. $M$ are all cells that fill the central portions of the lobules of the glomeruli and are what Sakaguchi has called the mesangium. As noted by Sakaguchi25) mesangium consists of two elements i. e. the mesangial cell and mesangial matrix. And these can be seen in Figure 24. Mesangial matrix is an amorphous substance with a density like that of the basement membrane and is observed between the thin endothelial cells and the mesangial cells or between the basement membrane, and the mesangial cells. The mesangial cell is rich in endoplasmic reticulum and high in cytoplasmic density. Yamada, and Takagi29) considers the mesangial matrix as a reticular arrangement of the basement membrane surrounding mesangial cells. Arrangement of the structural components of the glomerular capillary lumina from the side of Boman's space is, the epithelial cells, the basement membrane, the endothelial cells and the mesangium. In other words, the position of the mesangium in the structural arrangement is exactly the same as that of the glomerular anlage cells in an immature glomerulus. 
From this fact it may be suggested that the mesangial cell is a cell differentiated from glomerular anlage cells. Results of general observations made above of the process of glomerular development is shown in Text Figure 1.

(1) Directly beneath the inner layer (prospective epithelial cell layer) of the metanephrogenic vesicle appear the mesenchymal cells (glomerular anlage cells). The blood channel is formed in the space between the anlage cells.

(2) The basement membrane formates between the inner layer and the anlage cells. Anlage cells proliferate and as a result of the increase in blood quantity flowing the inter cellular space, the cells facing the space flatten and begin to take the shape of endothelial cells. The blood cavity walls made in this fashion are unsymmetrical in construction as Yajima has pointed out and differ from that of an ordinary capillary.

(3) The basement membrane gradually covers the outer layer of the metanephrogenic vesicle (Bowman's capsule) and the renal tubule cells in continuance with the basement membrane already formed between the inner layer cells and the glomerular anlage cells.

The glomerular anlage cells continue to proliferate and successively differentiate into endothelial cells creating new blood cavities. The differentiation of the inner layer cells into epithelial cells also becomes conspicuous.

(4) Glomerular differentiation becomes active, blood cavities conspicuously enlarge as result of increase in quantity of blood flow. As glomerular anlage cells actively differentiate into endothelial cells, the relative number of the two kinds of cells becomes reversed and the number of anlage cells becomes less than the number of endothelial cells. Mesangial matrix clearly appears (will treat on later) and anlage cells start showing characteristics of mesangial cell. In other words mesangial cells thus made are more or less rich in endoplasmic reticulum and high in cytoplasmic density.

b) Detailed description of glomerular components

1) Epithelial cells

As noted in "Observation A" epithelial cells originate in the inner layer of the metanephrogenic vesicle and their differentiation in comparison to the other structural components start very early. This finding corresponds to Katsuno's report ${ }^{11}$ ). In the period when the glomerular capillary formation is active the epithelial cells change from the heretofor comparatively simple structured cells into cells rich in endoplasmic reticulum ${ }^{17) 18)}$ and simultaneously pedicel formation becomes brisk. The apical portion of the epithelial cells becomes round and the basal portion flattens. (Figures 12, 13, 14)

The appearance of endoplasmic reticulum is active until 21 days after birth 

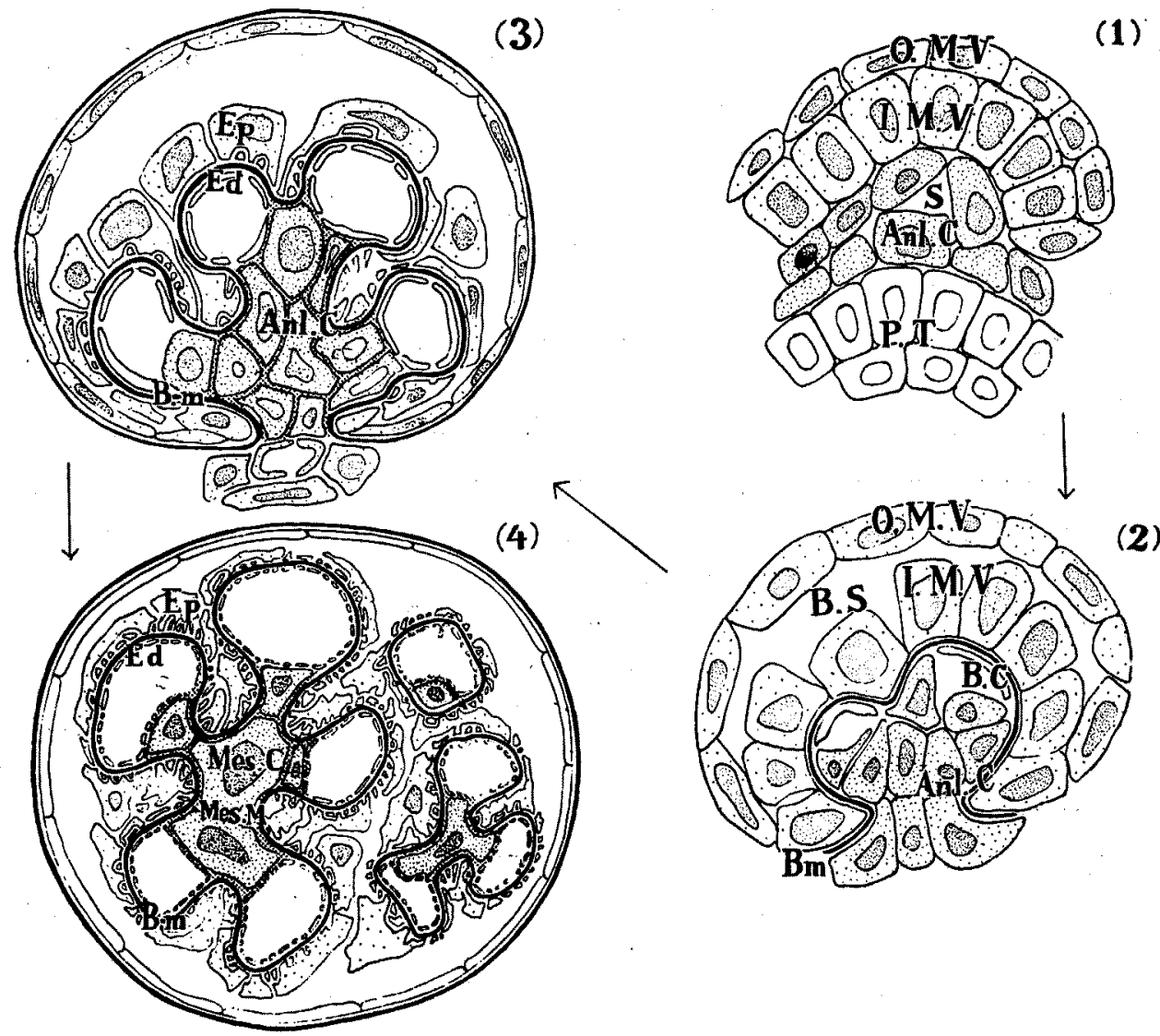

Text Fig. 1 Indicates that the differentiation of glomerular components is as indicated by arrows. Refer to Observation B) a).

O.M. V: The outer layer of metanephrogenic vesicle.

I. M.V : The inner layer of metanephrogenic vesicle.

P.T: Primitive renal tubule.

S : Intercellular space of glomerular anlage cells.

B. C : Blood cavity.

Anl.C : Glomerular anlage cell.

Bm : Basement membrane.

Ep : Epithelial cell.

Ed : Endothelial cell.

Mes. C: Mesangial cell.

Mes. M: Mesangial matrix.

(weaning period) but after that it decreases. The differentiation of the pedicel (Hall) which is considered to be a peculiar organella seen in the epithelial cell, starts with an infolding of cell membrane at the basal portion of the epithelial cell. (Figures 11, 12)

The rough surfaced endoplasmic reticulum that starts to appear conspicuously within the epithelial cell is thought to have close relation to the differentiation of 
the pedicels but to date immediate relationship between the morphogenesis of the pedicel and the rough surfaced endoplasmic reticulum has not been made clear. The arrow in Figure 13 shows the space made by the infolding of the cell membrane. This space resembles the space seen in between mature pedicels. The basal portion of the epithelial cell as seen in Figure 15 shows the main cytoplasmic mass and although continuity between portion A and portion $B$ is nol clear in this photograph it is safe to consider that it would be connected if seen tri-dimentionally. $\mathrm{C}$ shows the fact that, the spaces between the pedicels open towards Bowman's space.

Concerning pedicels arrangement (excepting peripheral portions of epithelial cells) the author from the viewpoint of their structural differentiation does not agree with the thought that pedicels are an interlocking of two adjacent epithelial cells, but considers that at least the pedicels within the main cytoplasmic mass of the epithelial cells are comparable to the compartments ${ }^{2124}$ in the renal tubule cells and the space between the pedicels are the same as that of the basal intussusception'2124)28). Text Figure 2 is a diagram showing the differentiation process of the pedicels as explained above. The arrows in Figure 16 show the membranous structure (filtration slit membrane-Yamada) covering the space between the pedicels. This membranous structure is not clear at the time when the infolding of the cell membrane is prominent but starts to become conspicuous when the shape of the pedicel becomes completed i. e. when the glomerular filtration becomes active. It is not clear whether this membranous structure is part of the epithelial cell membrane or whether it belongs the basement membrane. However there is no mistake that it is a kind of glomerular filtration membrane.

2) Basement membrane

As noted in "Observations A" basement membrane appears in between the inner layer of the metanephrogenic vesicle and the glomerular anlage cells. Figure 17 shows the basement membrane that has appeared between the inner layer and the endothelial cells. At this early stage the basement membrane does not have a membranous structure but when seen under the electron microscope it seems as though amorphous substances have filled the space between the inner layer and the glomerular anlage cells. When the glomerular anlage cells most actively differentiates into endothelial cells, the space between the epithelial cells and the endothelial cells is often quite large and therefore the width of the space occupied by the amorphous substances (primitive basement membrane) is not necessarily stable. Later the outer layer and renal tubule cells also become covered by basement membrane in continuance. As development progresses the three layer structure, with lamina densa in the middle and lamina rara interna and lamina rara externa 

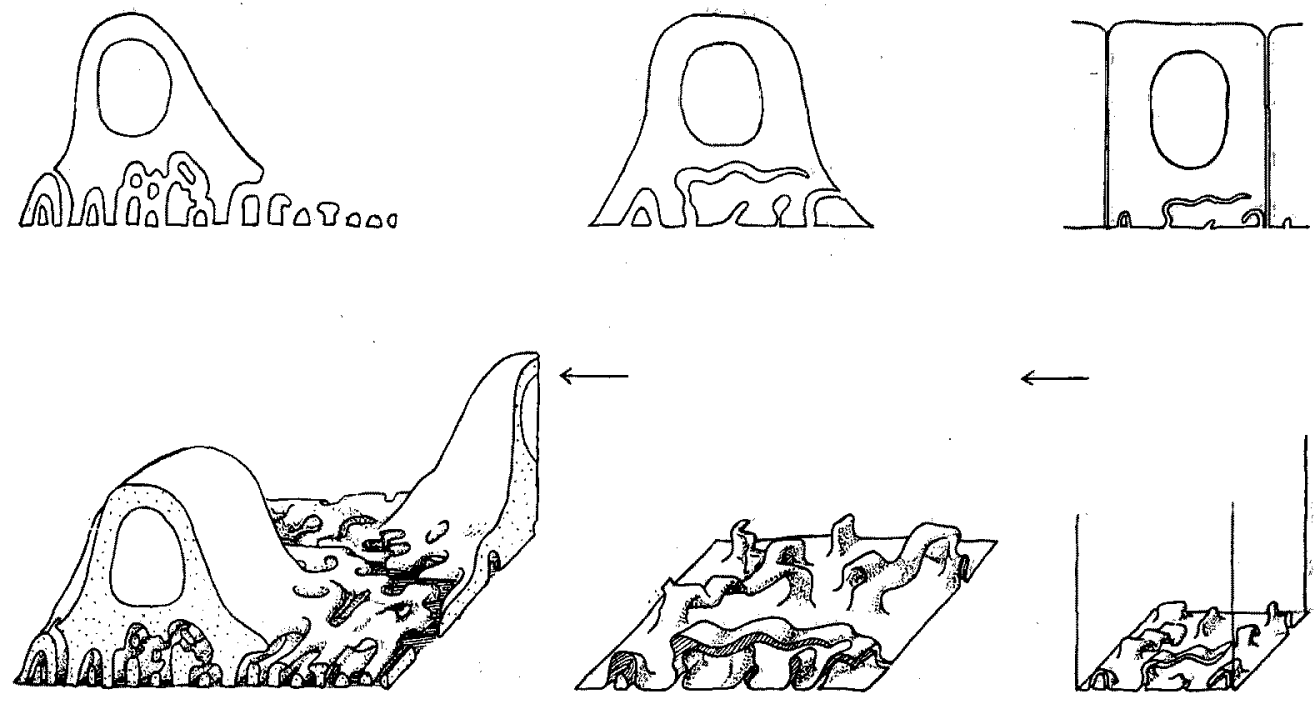

Text Fig.2

Text Fig. 2 Indicated that pedicels is formed as indicated by arrows. This also indicates that the pedicels within the main cytoplasmic mass of the epithelial cells are resemble the compartments in the renal tubule cells and the spaces between the pedicels are same as that of the basal intussusception.

(Yamada) on both sides, becomes apparent, as seen in Figure 18. However their thickness is $0.01 \mu, 0.02 \mu, 0.02 \mu$, respectively, and is one third of that of a mature basement membrane shown in Figure 19. In an immature glomeruls, lamina densa is occasionally seen as a double layer and this tendency is apt to be strong when the space between the epithelial cells and the glomerular anlage cells (or mesangial cells) is large, and is particularly seen near the mesangial cells. The basement membrane thickens upon maturation of the glomerulus and in specimens of 21 days after birth the basement membrane is almost as thick as a mature basement mem. brane. Filamentous structures are not observed in the lamina densa at any stage of development.

3) Endothelial cells

It has already been noted that endothelial cells are formed by flattening of the glomerular anlage cells which takes place immediately below the basement membrane.

Ed in Figure 21 indicates endothelial cells directly facing a blood cavity. Anl. C indicates glomerular anlage cells. As is apparent in this photograph a small number of mitochondria and endoplasmic reticulum is seen in both cells, and the 
cells closely resemble each other. In Figure 22 the endothelial cells have flattened and in one portion the formation (arrow) of endothelial pores (Sakaguchi) (endothelial filtration pores (Yamada)) can be seen. Figure 23 shows the endothelial filtration pores showing a uniform distribution. However the formation process of these pores is unknown. However before these pores are formed endothelial cells start flattening which is thought to be the result of increase in the quantity of blood flow.

4) Mesangium

Figure 24 is a mesangium of a mature glomerulus. Ed indicates the endothelial cells; $\mathrm{CL}$ glomerular capillary lumina, Mes. $\mathrm{C}$, the mesangial cell ; and Mes. Mat indicates what Sakaguchi calls the mesangial matrix. (Basement membrane like material (Farquher $\left.{ }^{5)}\right)$ ). Neither collagen fibres nor myofilaments can be seen in the cytoplasm of the mesangial cell or in the mesangial matrix. Mesangial cells as compared to the endothelial cell hold more endoplasmic reticulum in its cytoplasm. Many mesangial cells show complicated projections of the cytoplasm. Electron microscopically mesangial matrix shows a similar density as the basement membrane and fills the spaces between the basement membrane and the mesangial cells, and between the endothelial cells and the mesangial cells. The matrix consists of amorphous substances and fills the irregular spaces between the mesangial cells and other structural elements but is not shaped like a membrane. In other words the matrix is a structural component closely resembling the basement membrane but something which should be treated quite differently.

Figure 25 shows further differentiation than Figure 21. The endothelial cells (Ed) have flattened conspicuously, mesangial matrix has started to appear between the basement membrane and the mesangial cells, between the endothelial cells and the mesangial cells, or between the cytoplasmic projections of the mesangial cells. Mesangial matrix starts formation around the mesangial cells after the basement membrane can be clearly observed. As can be seen in Figure 24 it does not necessarily surround the mesangial cells completely even in a mature glomerulus.

\section{DISCUSSION}

Of glomerulogenesis Herring9) thought the inner layer of the metanephrogenic vesicle formed the glomerular anlage cells, and the anlage cells then formed the glomerulus in situ. Recently Lewis ${ }^{13) 14}$ ) has agreed with this theory. On the other hand Toldt ${ }^{30}$ ) thought that the glomerulus is formed by the capillary loops invaginating the Bowman's capsule. Edwards ${ }^{3)}$ on the whole agrees with Toldt's theory and thinks that the tip of the renal artery branch which ends in a blind end, buds and branches out, and then rejoins while invaginating the Bowman's capsule, 
becomes vas efferens and further arteriola rectae renalis and descends the medulla. Hall $^{8)}$ and Kurz ${ }^{12)}$ who have studied the differentiation of the glomerulus by electron microscope both believe that the glomerulus is formed in situ. The finding of the present study also supports the view that the glomerular anlage cells first form the intercellular space which late becomes glomerular capillary beneath the inner layer of the metanephrogenic vesicles. However two or three points must be considered before wholeheartedly agreeing to Lewis' theory which says the glomerular anlage cells are originated from the inner layer. Of course as can be seen in Figure 5 and Figure 6, in the earliest stage of the glomerular development the basement membrane has not yet made its appearance, and part of the anlage cells appear to be a intermediate form between the anlage cells and the inner layer cells. This finding seems to confirm Lewis' theory. However this finding can be interpreted in another way; i. e. that the mesenchymal cells differentiated directly from the metanephrogenic tissue, proliferated immediately below the inner layer of the vesicle and formed the glomerular anlage cell. According to the author's observation the light microscopic photograph presented by Lewis is electron microscopically a formative stage of the glomerulus when immature basement membrane has already appeared immediately below the inner layer. Erythrocytes, reticulocytes can be observed in the glomerular anlage lumen_-it is still like an intercellular space-as seen in Figure 5 , but this fact suggests a possible communication of the early blood cavities in the glomerular anlage cells with the sinusoid (which later becomes vas afferens and vas efferens) formed in the renal cortex as indicated by Lewis, exists from its early stages.

$\mathrm{Kur}^{8}$, and Halli2) surmise that the erythrocyte are formed in situ within the glomerulus but the author could not observe a distinct transition from anlage cells to red blood cells.

Hall considers that the intracytoplasmic vesicles of the endothelial cells become glomerular capillary lumina by their joining but the author has observed many instances where the flattening endothelial cells composing the lumina are connected by their lateral cell membranes, and therefore suggests that the endothelial cells themselves flatten to form the lumina walls. The vesicle (endoplasmic reticulum) seen within the cytoplasm of the endothelial cells may rather have some role in flattening endothelial cells or in the formation of the endothelial filtration pores.

What is the reason that in spite of the fact that the glomerular pattern gradually becomes more complicated from the earliest stage of glomerulogenesis to the mature glomerulus, the arrangement of the components constructing the glomerular capillary lumina does not change. The author interpretes this as follows: proliferation of anlage cells and formation of blood cavities beneath the basement 
membrane continue even after the basement membrane has appeared between the inner layer and the glomerular anlage cells, and the increase of blood flow in the cavities results in the dilation of the blood cavities. Although the "ins and outs" on the surface of the glomerular anlage system become more pronounced (the curves become more sharp) as the cavities dilate the epithelial cells actively produce more pedicels, strech the periphery of their cytoplasms and enlarge their surface space contacting the basement membrane so that the epithelial cells can completely cover the basement membrane. Therefore however complicated the "ins and outs" of the glomerular anlage system become, the epithelial cells are always able in this manner to cover the outside of the basement membrane. Further, the differentiation of anlage cells into endothelial cells, i. e. the formation of blood cavity-is always performed immediately beneath the basement membrane, and therefore the anlage cells always take their position in the inner side (the vascular pole side) of the endothelial cells. Up to a certain time, the anlage cells proliferate parallel to the growth of the glomerulus, produce new blood cavities beneath the basement membrane, and show an increasingly complicated glomerular pattern but once past that period (the author cannot as yet set exactly the time when the period ends), the differentiation of anlage cells to endothelial cells ends, and the anlage cells remain as mesangial cells surrounded by the mesangial matrix that has started to appear around it and takes up the role of supporting the blood cavities. Therefore from the early stages of glomerular differentiation to the period of maturity, the arrangement of the structural components that are arrayed along the cavity walls remain constant, although the terms describing them may change....i. e. from inner layer cells to epithelial cells, and from anlage cells to endothelial cells and/or mesangial cells.

Yamada ${ }^{31}$ ) reports that myofilaments exist in the cytoplasm of the mesangial cells but in accordance with Meuller15), no myofilaments could be observed in the materials of present study. However, although myofilaments and collagen fibres may not be observed in the mesangium (which is composed of the mesangial cell and mesangial matrix), and although mesangial cell may be differentiated embryologically from the same origin as the endothelial cells as the author has pointed out in his observations, the author would like to accept the mesangium as an important component of the glomerulus because of the following points. 1) The mesangium within the glomerulus takes the position of supporting the blood cavities surrounded by endothelial cells. 2) The existance of mesangial matrix around the mesangial cells. 3) The fact that mesangial cells as compared with the endothelial cells proliferate conspicuously when Masugi nephritis occurs 26 ) - this fact can be explained from the author's observations that the mesangial cells are a much more undifferen- 
tiated type of cell as compared to endothelial cells and is nearer in structure to the mesenchymal cells. 4) An electron microscopic photograph of the nodular lesion which often appears in the glomerulus of Kimmelstiel Wilson's disease shows that mesangial matrix together with mesangial cell distincly increase 27 .

At present most electron microscopists believe that the basement membrane of an adult glomerulus is composed of a single membrane. Among electron microscopists Kurz calls attention to the fact that in the embryo of human being the basement membrane can sometimes be observed to double, and this fact indicates that the membrane is formed by both the epithelial cells and the endothelial cells. As the author has reported in his observation he also has observed the same finding by the electron microscope. However this finding is occasional and in many cases the basement membrane is composed of a single layer, and in the glomerular lesions (i. e. in Masugi nephritis and/or Kimmelstiel-Wilson's disease) the basement membrane has never been seen electron microscopically as a double membrane ${ }^{26 / 27}$. Therefore, this does not substantiate Jone's ${ }^{10)}$ theory.

Yamada and Takagi considers the mesangial matrix as basement membrane that is spread reticularly around the mesangial cells, while Farquhar calls it a basement membrane like structure. The author would like to comment on the above as follows: (1) Embryologically the mesangial matrix appears later than the lamina densa (basement membrane). (2) The mesangial matrix seems to be important as a structural component that supports the glomerular capillary wall. (3) As stated in author's observation B the mesangial matrix does not fill the conception of a membrane. From these points, the author suggests that although the mesangial matrix strongly resembles the basement membrane in structure, it should be handled under a different conception.

Since the observations using serial section have not yet been successful, the complicated blood channels within the glomerular anlage system, the tri-dimentional connections between afferent arterioles efferent arterioles and the glomerulus still. remain unclarified.

\section{SUMMARY}

1) The author has observed by electron microscope the glomerular differentiation of rats.

2) Glomerular capillary is formed by the glomerular anlage cells which appear beneath the inner layer of the metanephrogenic vesicle.

3) Glomerular anlage cells proliferate immediately below the inner layer and form intercellular space and later on blood cavities. From a very early stage these intercellular spaces or blood cavities have communication with sinusoids which exist 
in the renal cortex.

4) Basement membrane appears between the inner layer and glomerular anlage cells. The anlage cells further proliferate and successively produce new blood cavities in continuation with the first blood cavity immediately under the basement membrane.

5) As glomerulus develops the glomerular pattern grows more complicated but the arrangement of the components that compose the cavity walls remain unchanged from the early stages of immature gromerulus to maturity.

6) The differentiation of the glomerular structural components i. e., epithelial cells, basement membrane, endothelial cells and mesangium has been treated on.

The author would like to express his grateful appreciation to Prof. T. Kobayashi. The author also is indebted to Dr. H. Sakaguchi for his help and advice.

\section{REFERENCES}

1. Allen, A. C.: The Kidney, medical and surgical disease. Grune \& Stratton, 1951.

2. Arataki, M.: Am. J. Anat., 36: 399, 1926.

3. Edwards, J. G.: Anat. Rec., 109: 495, 1951.

4. Farquhar, M. G.: Schweiz. Med. Wschrift, 87: 501, 1957.

5. Farquhar, M. G.: Am. J. Path., 33: 791, 1957.

6. Hall, B. V.: Anat. Rec., 120: 733, 1954.

7. Hall, B. V.: Am. J. Path., 30: 646, 1956.

8. Hall, B. V.: Electron Microscopy, proceedings of the Stockholm Conference, 1956.

9. Herring, P. T.: J. Path. Bact., 6: 459, 1900.

10. Jones, D. B.: Am. J. Path., 27: 991, 1951.

11. Katsuno, R.: Nihon Sanfujinka Zasshi, (Japanese), 4: 702, 1952.

12. Kurz, S. M.: Exp. Cell. Reser, 14: 335, 1958.

13. Lewis, O. J.: J. Anat., 92: 92, 1958.

14. Lewis, O. J.: J. Anat., 92: 433, 1958.

15. Mueller, C. B.: Am. Heart. J., 55: 309, 1958.

16. Patten, B. M.: Human Embryology. Megraw Hill Book Company, 1946.

17. Palade, G. E.: J. Biophysic and Biochem. Cytol, 1: 56, 1956.

18. Palade, G. E.: J. Biophysic and Biochem. Cytol, 2: (Suppl.) 85, 1956.

19. Peace, D. C.: Anat. Rec., 118: 339, 1954.

20. Peace, D. C.: Anat. Rec., 121: 701, 1955.

21. Peace, D. C.: J. Histochem. Cytochem., 3: 295, 1955.

22. Rhodin, J.: Exper. Cell Res., 8: 572, 1955.

23. Rinehart, J. R.: Arch. of Path., 59: 439, 1955.

24. Ruska, H.: J. Biophysic and Biochem. Cytol., 3: 249, 1957.

25. Sakaguchi, H.: Keio J. Med., 4: 103, 1955.

26. Sakaguchi, H.: Acta Path. Jap, $7: 53,1957$.

27. Sakaguchi, H.: Japanese Pathological Society, 1958.

28. Suzuki, Y.: J. Elect. Mic., 6: 52, 1958.

29. Takagi, F.: Japanese Pathological Society, 1958.

30. Told, C.: Akad. Wiss. Wien, 69, 123: 150, 1874.

31. Yamada, E.: J. Biophysic and Biochem. Cytol, 1: 551, 1955. 
32. Yajima, G.: Igakunoayumi, (Japanese), 20: 359, 1955.

33. Zimmerman, K. Z.: Zeitsch. Mikroskop. Anat. Vosch, 32: 176, 1933.

\section{EXPLANATION OF PLATES}

Fig. 1. A light microscopy of the earliest stage of glomerulogenesis.

MT: Metanephrogenic tissue.

I. M.V: The inner layer of metanephrogenic vesicle.

B.S: Bowman's space.

O.M.V: The outer layer of metanephrogenic vesicle (specimen No. 1)

Fig. 2. A light microscopy which shows glomerular anlage cells appearing immediately below the inner layer of metanephrogenic vesicle.

Anl. C: Glomerular anlage cells (specimen No. 1)

Fig. 3. Immature glomerulus of which differentiation is more advanced than Fig. 2. (specimen No. 1)

Fig. 4. A mature glomerulus. PAS-stain (specimen No. 13)

Fig. 5. An electron microscopy of a primitive glomerulus corresponding to Fig. 1 .

I. M. V: The inner layer of metanephrogenic vesicle.

O.M.V: The outer layer of metanephrogenic vesicle.

B.S: Bowman's space.

$T$ : Transitional portion between the inner and outer layer.

Eryth: Erythrocyte.

Ret: Reticulocyte. (specimen No. 1) $\times 2,800$

Fig. 6. Part of Fig. 5 .

A : A mesenchymal cell. (glomerular anlage cell)

B : The inner layer cell.

C : This cell may be a intermediate cell between $A$ and B.? (specimen No. 1) $\times 8,100$

Fig. 7. Basement membrane appears between the inner layer and glomerular anlage cells. The anlage cells actively proliferate.

$\mathrm{Bm}$ : Basement membrane.

1. M. V: The inner layer of metanephrogenic vesicle.

O.M.V: The outer layer of metanephrogenic vesicle.

B. S: Bowman's space.

Anl. C: Glomerular anlage cells.

B. C: Blood cavity. (specimen No. 2) $\times 3,500$

Fig. 8. Shows further active proliferation of the glomerular anlage cells.

A : Glomerular anlage cells.

B : Glomerular anlage cells.

B. C: Blood cavity. (specimen No. 6) $\times 2,500$

Fig. 9. An electron microscopy corresponding to Fig. 3.
B. S: Bowman's space.
Ep: Epithelial cell.
B. C: Blood cavity.
Ed: Endothelial cell.
Anl. C: Glomerular anlage cell. (specimen No. 6) $\times 3,600$

Fig. 10. Mature glomerulus.

M: Mesangium.

A. a: Afferent arteriole. (specimen No. 13) $\times 2,600$

Fig. 11. Immature glomerulus cut perpendicularly to the vascular pole of glomerulus. The position of glomerulular anlage cells is exactly the same as that of mesangium as seen in Fig. 10.

Anl. C: Glomerular anlage cell.

Ep: Epithelial cell. 
Bm: Basement membrane.

Ed: Endothelial cell.

(specimen No. 5) $\times 2,800$

Fig. 12. Arrows show the infoldings of epithelial cell membrane.

$\mathrm{Bm}$ : Basement membrane.

Ed: Endothelial cell.

Ep: Epithelial cell.

(specimen No. 4) $\times 33,000$

Fig. 13. Arrow shows a somewhat dilated space formed by the infolding of epithelial cell membrane.

Ep: Epithelial cell.

$\mathrm{Bm}$ : Basement membrane.

Ed: Endothelial cell.

(specimen No. 3) $\times 32,000$

Fig. 14. Shows the process of differentiation of the pedicel. Arrow indicates that the space of pedicels is closely resemble to the space of basal intussusception. (specimen No. 6) $\times 32,000$

Fig. 15. A immature epithelial cell.

C indicates that the space of pedicels opens to Bowman's space, Both $A$ and $B$ seem to be connected with each other tri-dimentionally. (specimen No. 7) $\times 35,000$

Fig. 16. Arrow shows filtration slit membrane (Yamada).

Bm: Basement membrane. . Ep: Epithelial cell.

Ed: Endothelial cell. (specimen No. 7) $\times 40,000$

Fig. 17. Primitive basement membrane.

Bm: Basement membrane. Ed: Endothelial cell.

I. M.V: The inner layer cell (prospective epithelial cell). (specimen No. 1) $\times 32,000$

Fig. 18. Lamina densa, lamina rara externa and lamina rara interna can be observed.

Ep: Epithelial cell.

$\mathrm{Bm}$ : Basement membrane.

Ed: Endothelial cell. (specimen No. 6 ) $\times 33,000$

Fig. 19. Mature glomerulus.

Mes: Mesangium.

Ed. Endothelial cell.

$\mathrm{Bm}$ : Basement membrane $\quad$ Ep: Epithelial cell. (specimen No. 13) $\times 16,000$

Fig. 20. Arrow shows a double layer of lamina densa.

Ep: Epithelial cell.

Ed: Endothelial cell.

Mes: Mesangial cell.

Fp: The cytoplasmic process of mesangial cell.

Dotted arrows show the mesangial matrix. (specimen No. 7) $\times 40,000$

Fig. 21. Anl. C: Glomerular anlage cell.

Ed: Endothelial cell.

Bm: Basement membrane.

(specimen No. 3) $\times 15,000$

Fig. 22. Arrow shows the formation of endothelial pore.

Ed: Endothelial cell.

Ep: Epithelial cell.

Pd: Pedicel.

$\mathrm{Bm}$ : Basement membrane.

(specimen No. 7) $\times 33,000$

Fig. 23. Indicates that endothelial pores show a uniform distribution. (specimen No. 12) $\times 40,000$

Fig. 24. Mature glomerulus.

Ed: Endothelial cell.

Mes. Mat: Mesangial matrix.

Ep: Epithelial cell.

Mes. C: Mesangial cell.

$\mathrm{Bm}$ : Basement membrane.

CL: Capillary lumina. (sperimen No. 13) $\times 33,000$

Fig. 25. Shows the differentiation of mesangium.

Arrow: Mesangial matrix.

$\mathrm{Bm}$ : Basement membrane.

Mes. C: Mesangial cell,
Ed: Endothelial cell.

Ep: Epithelial cell.

Fp: The cytoplasmic process of mesangial cell. (specimen No. 6) $\times 40,000$ 


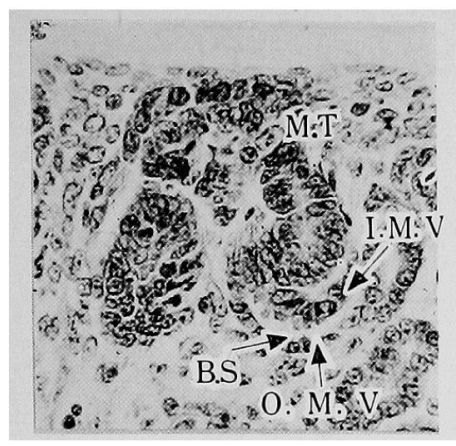

$\mathrm{Fig} 1$

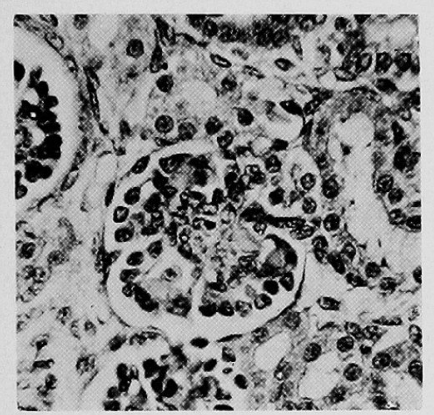

Fig 3

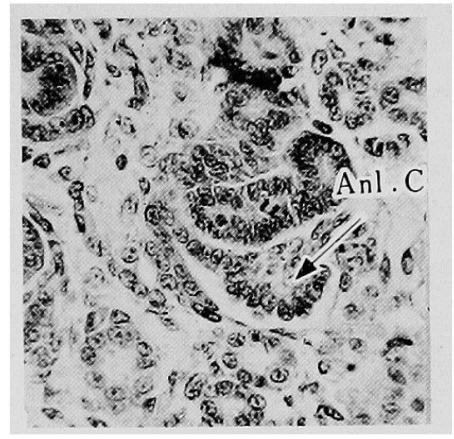

Fig 2

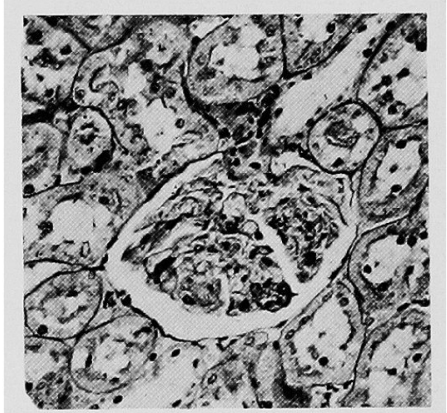

Fig 4

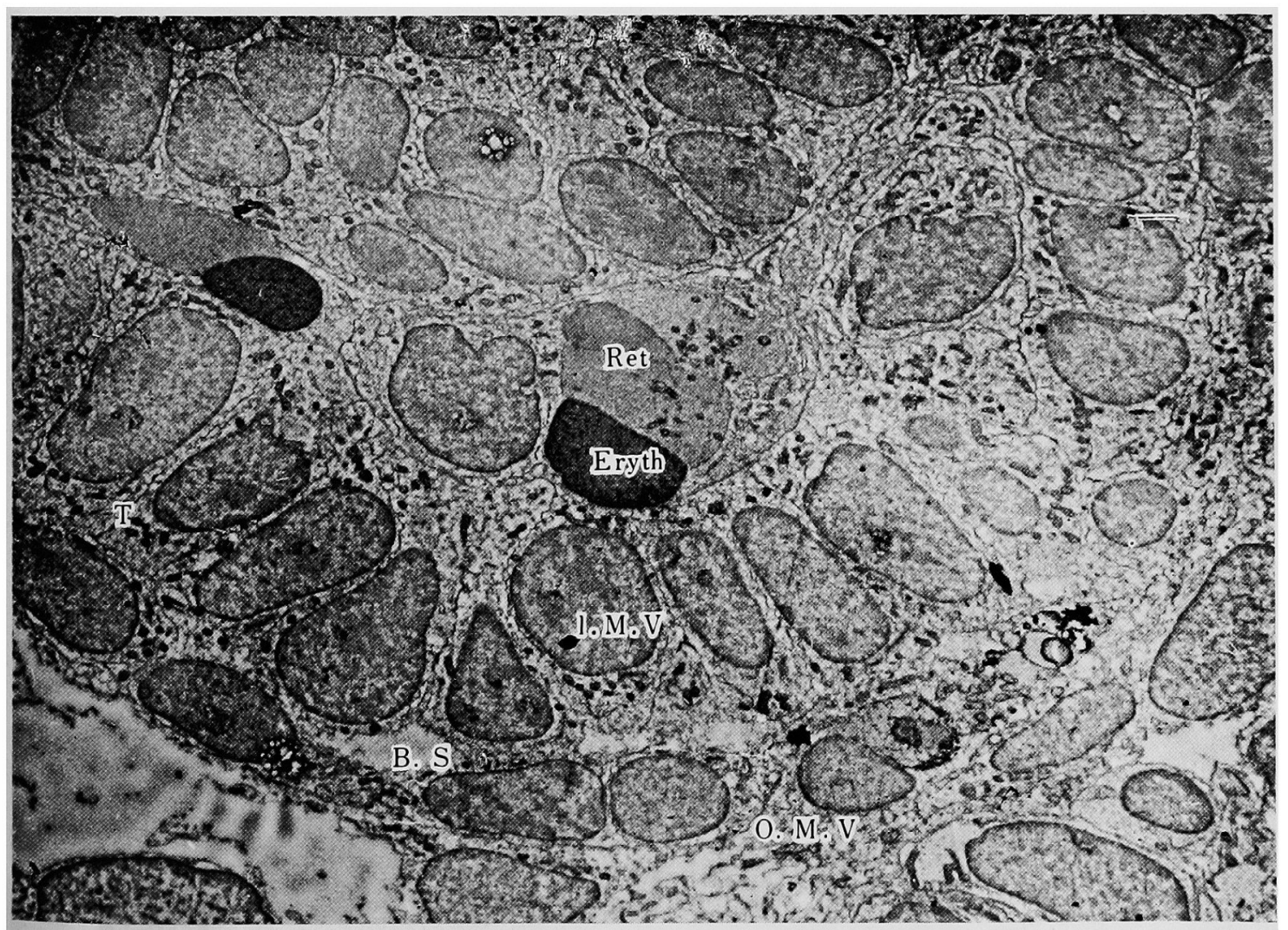




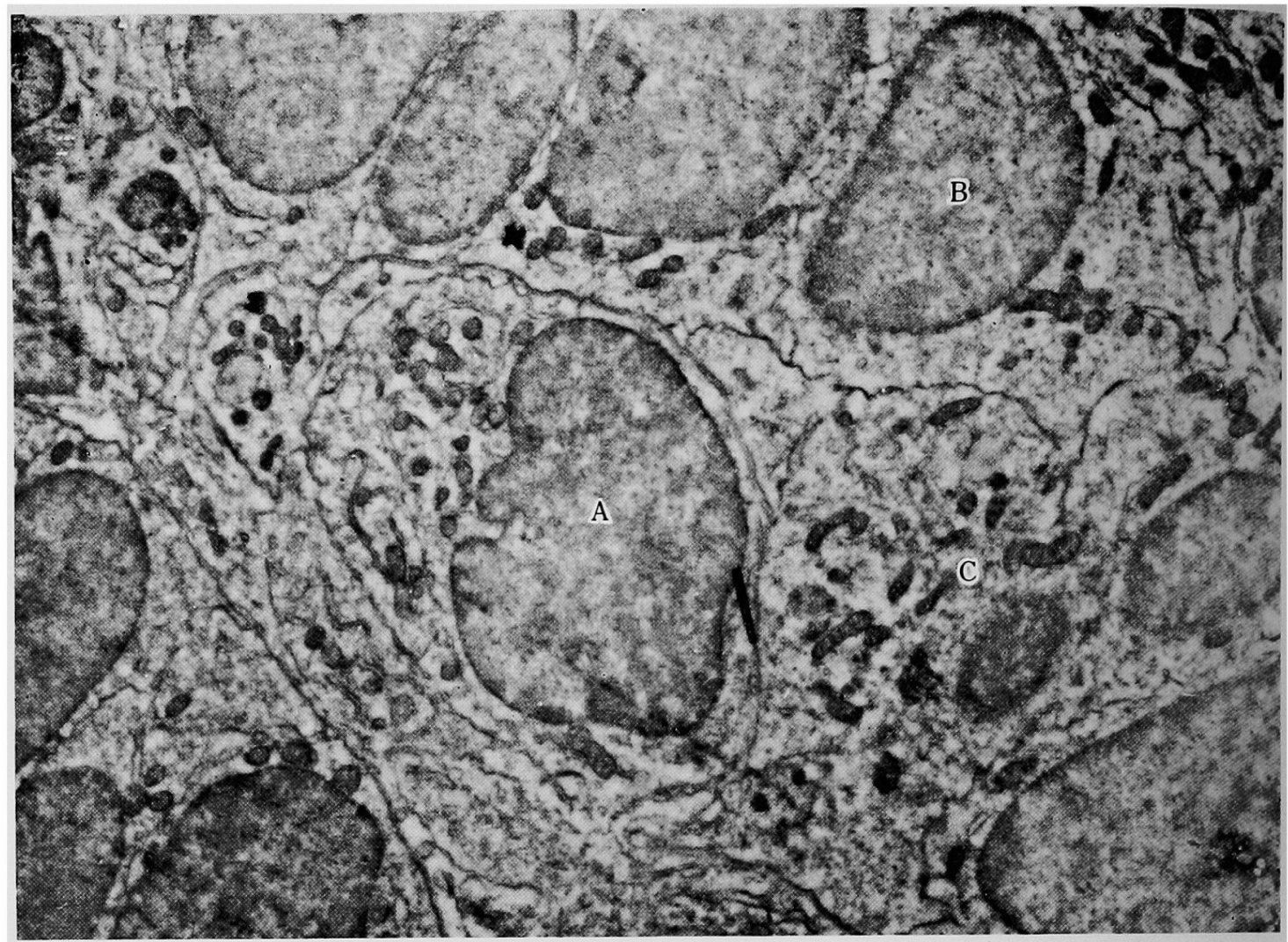

Fig 6

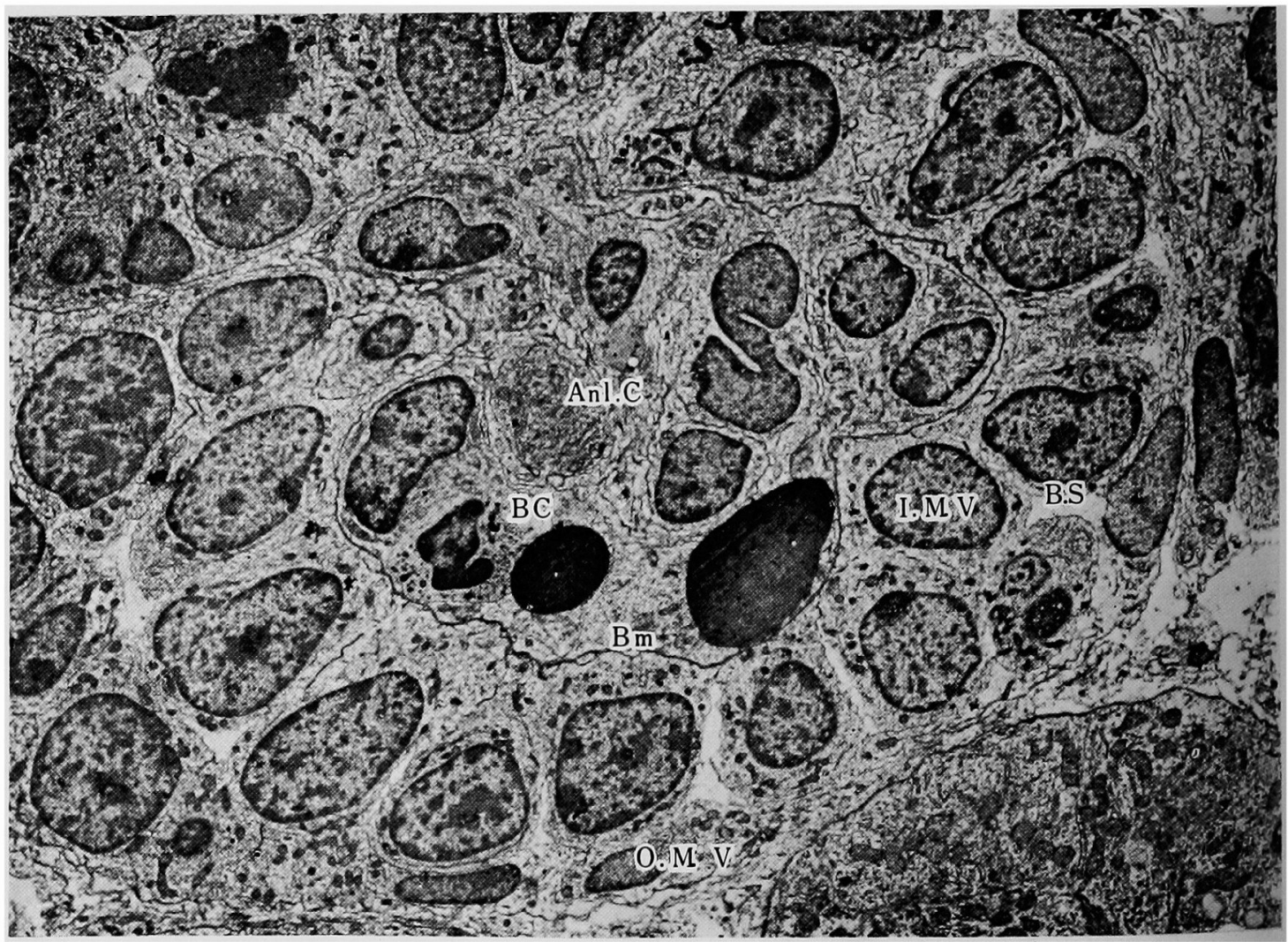




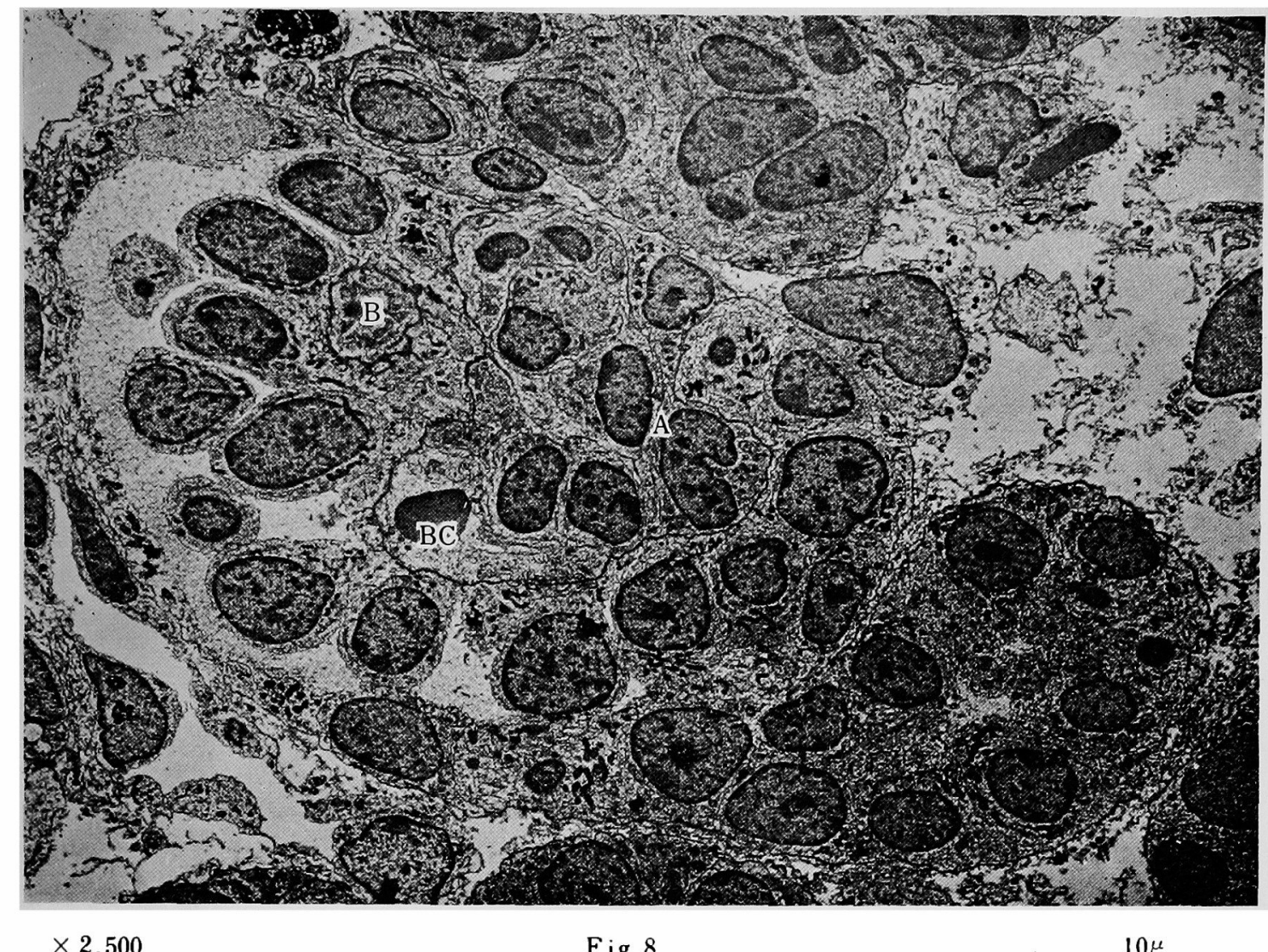

$\times 2.500$

Fig 8

$10 \mu$

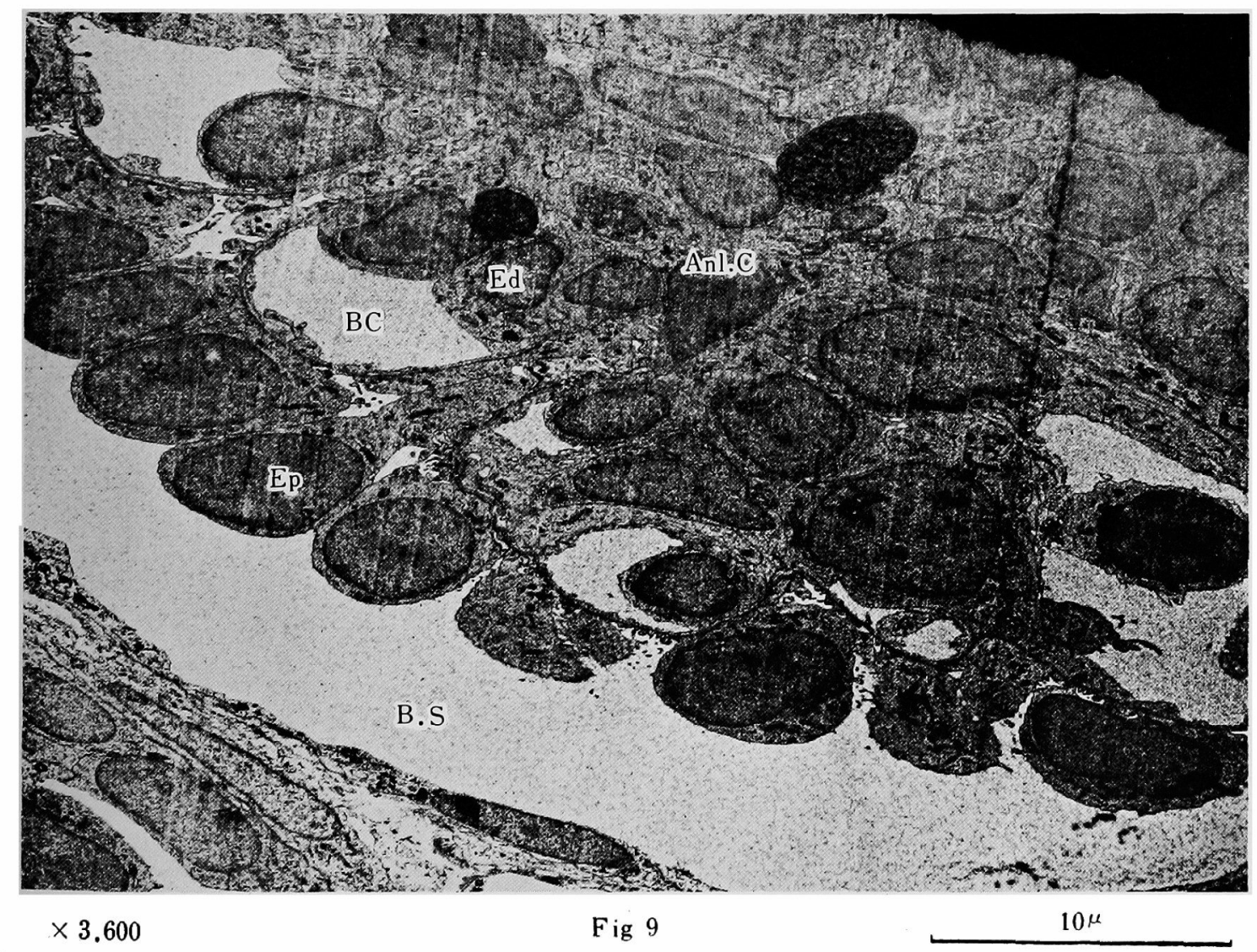




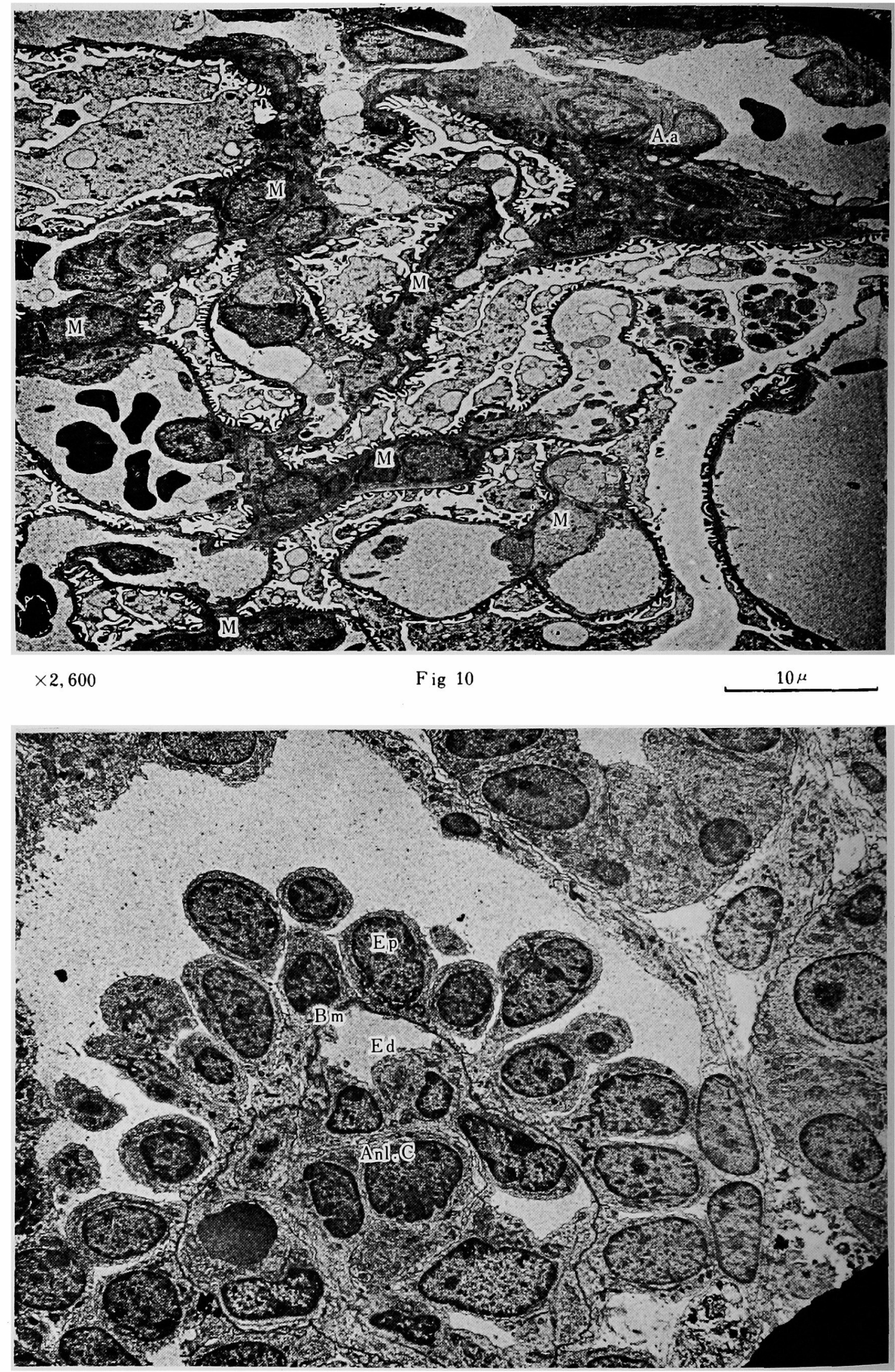




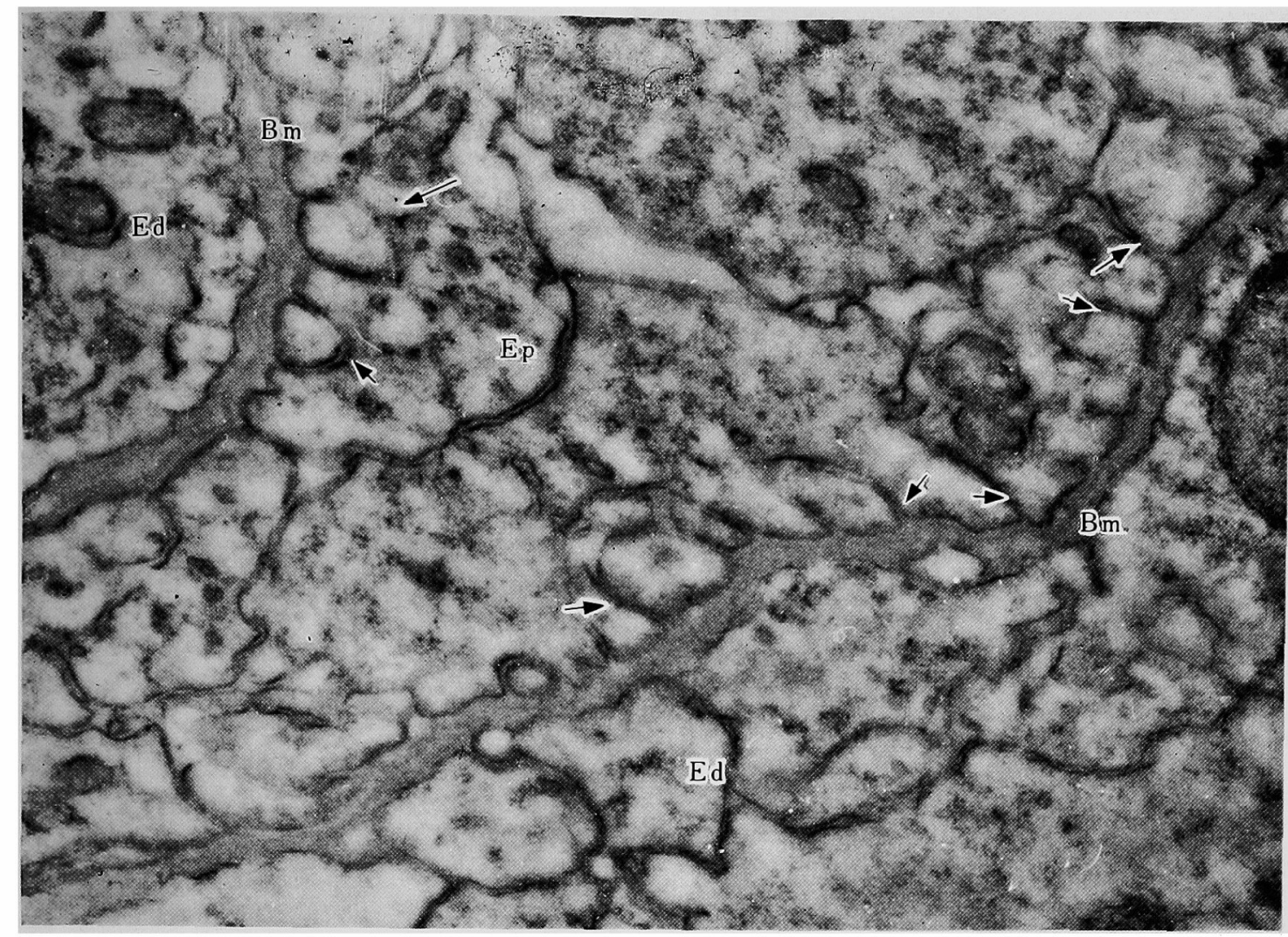

$\times 33,000$

Fig 12

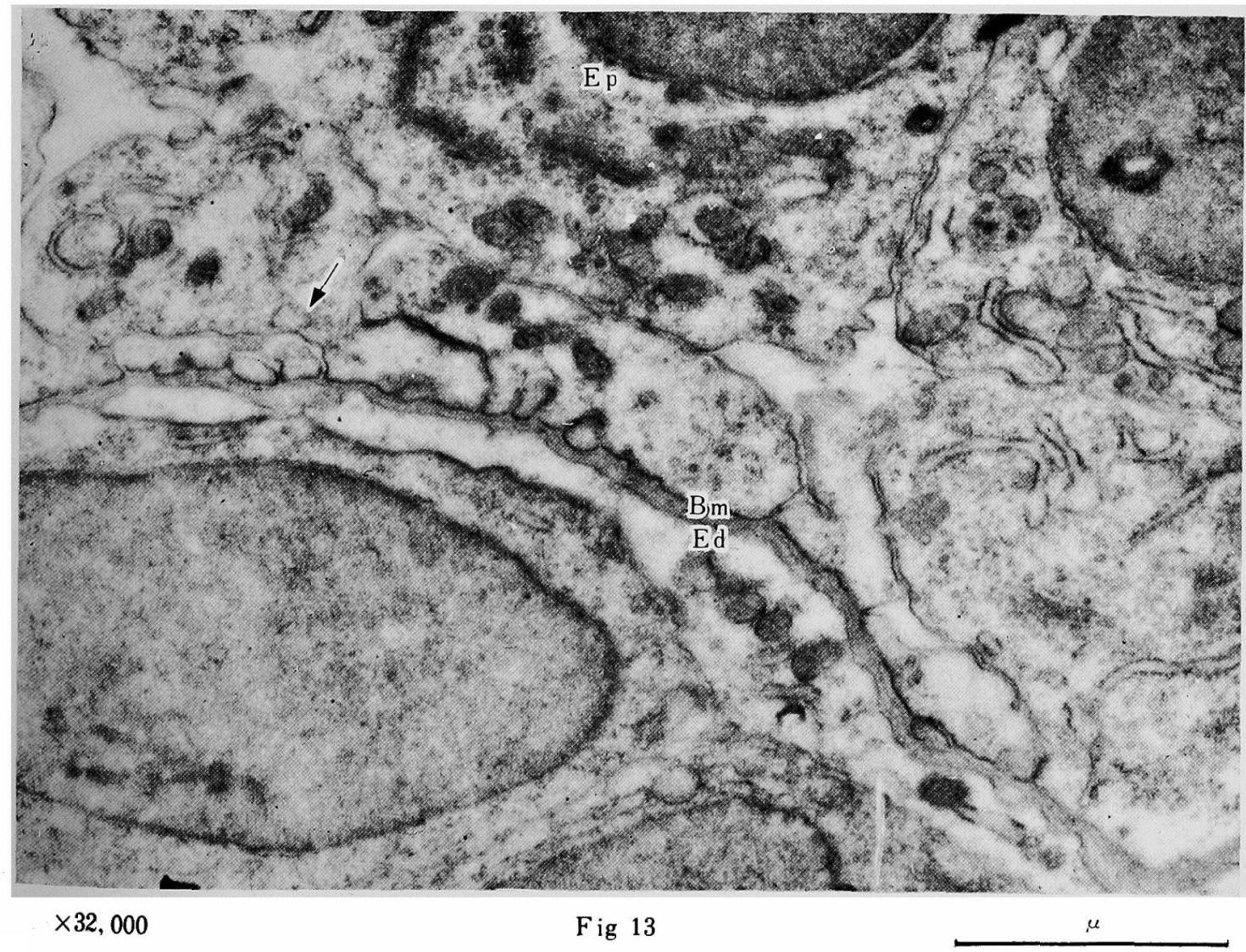




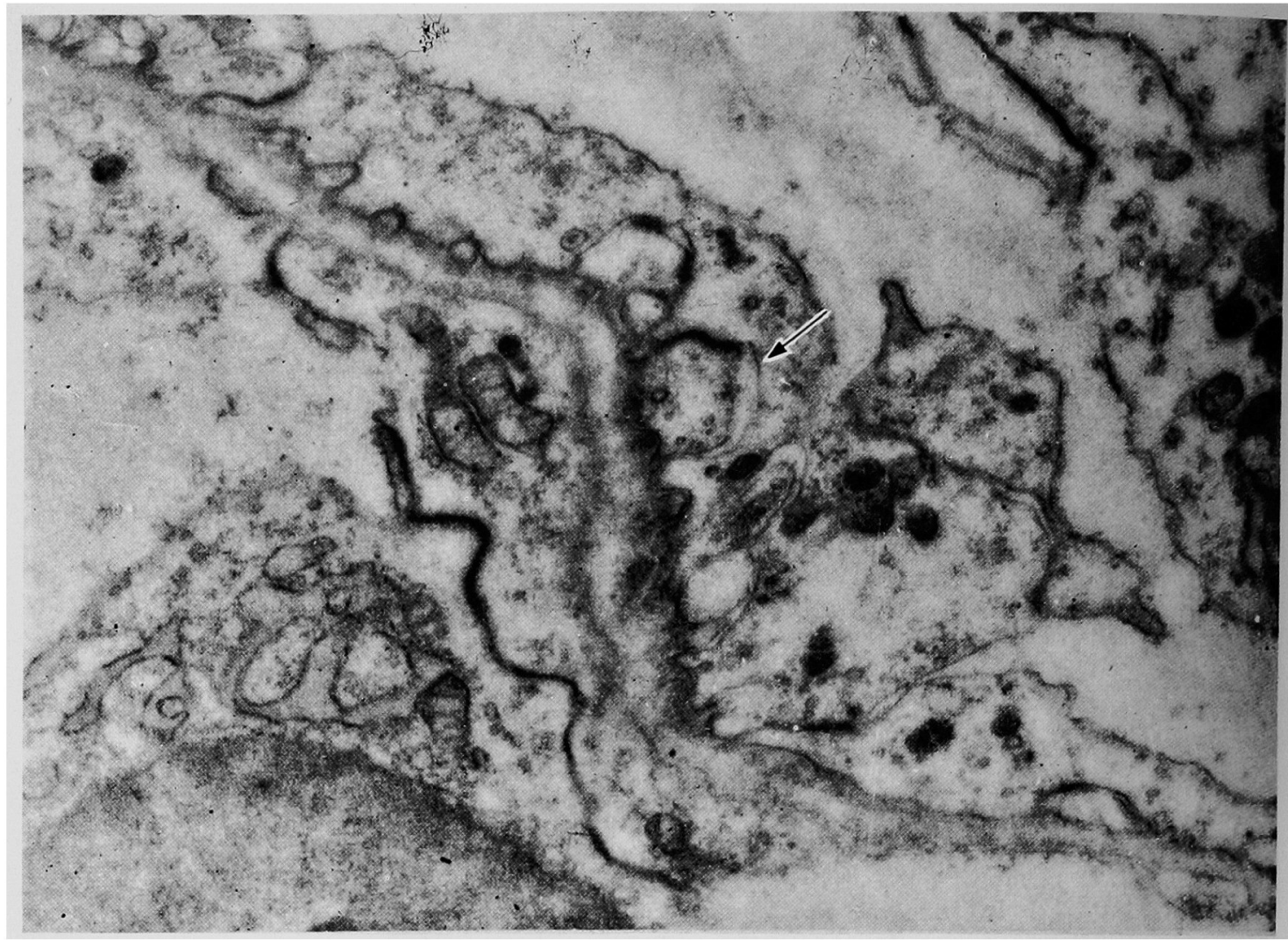

$\mu$

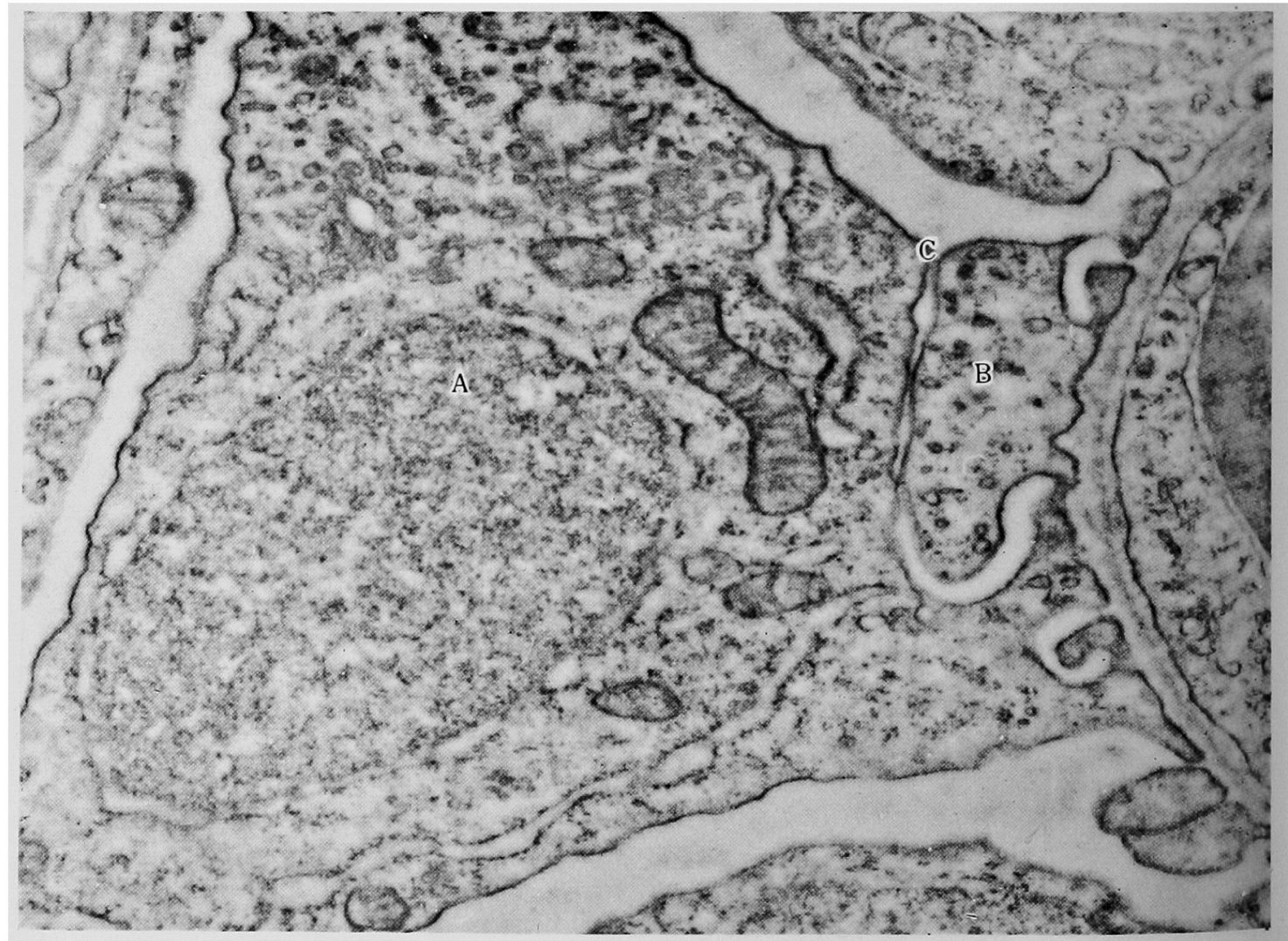



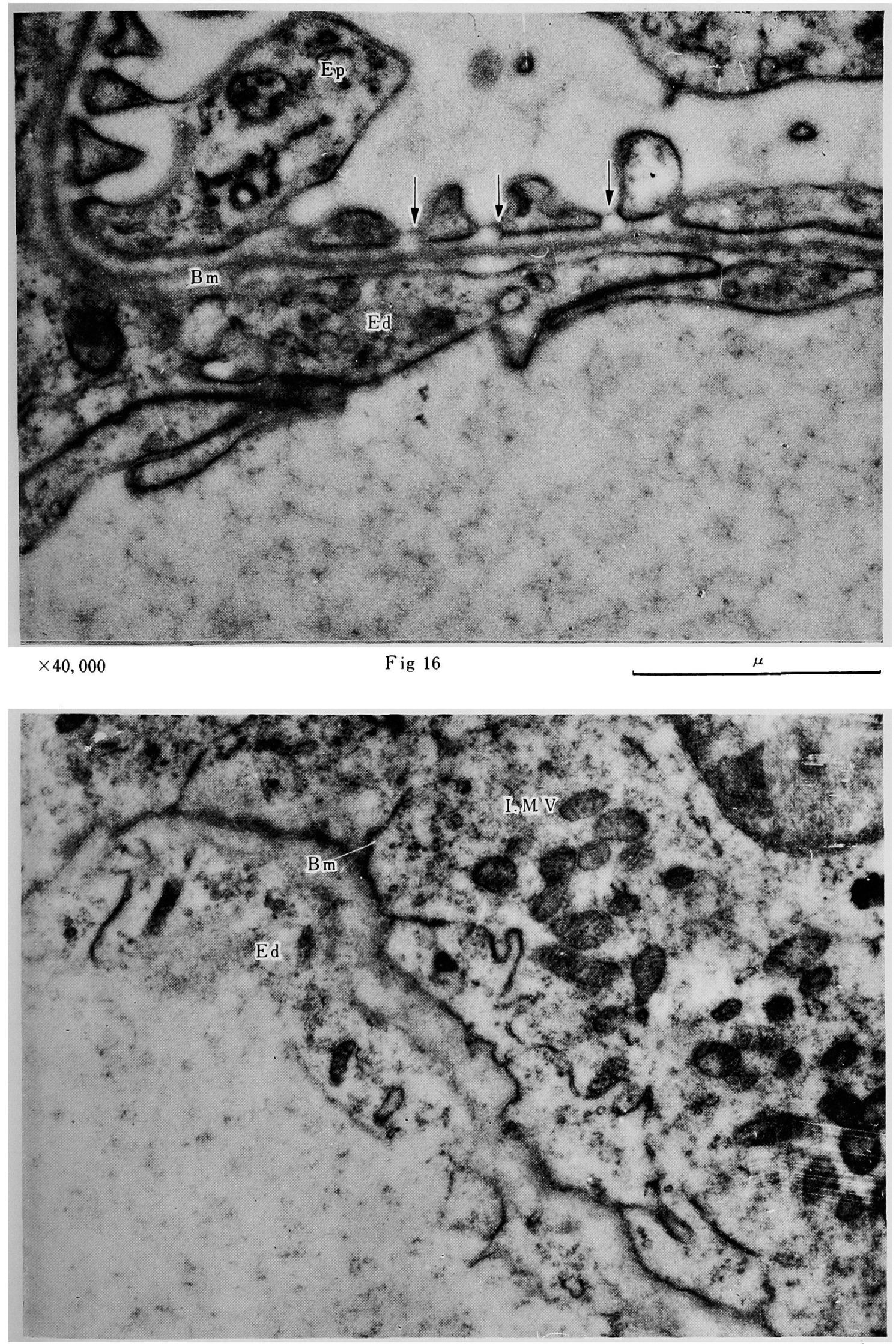

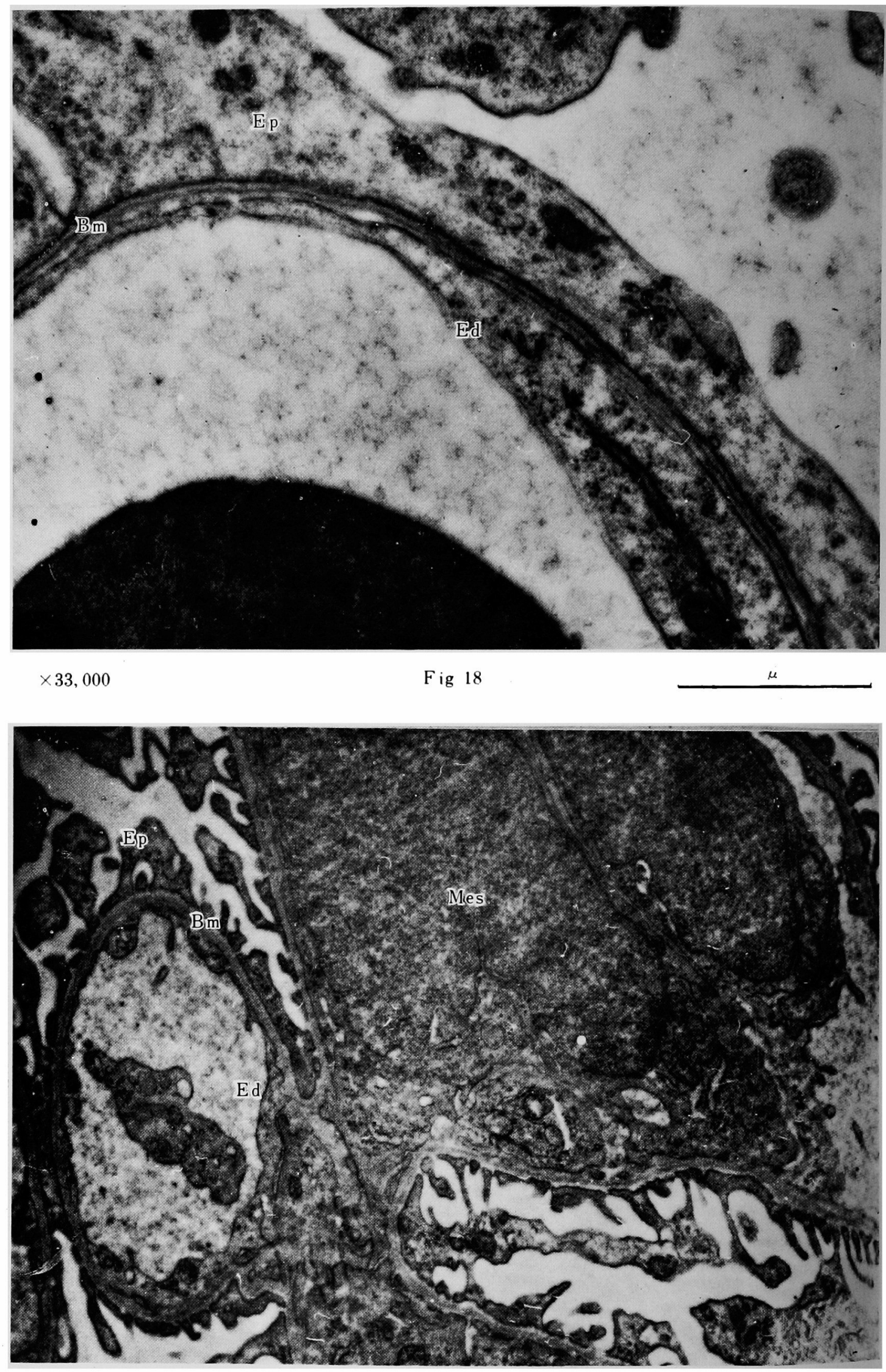


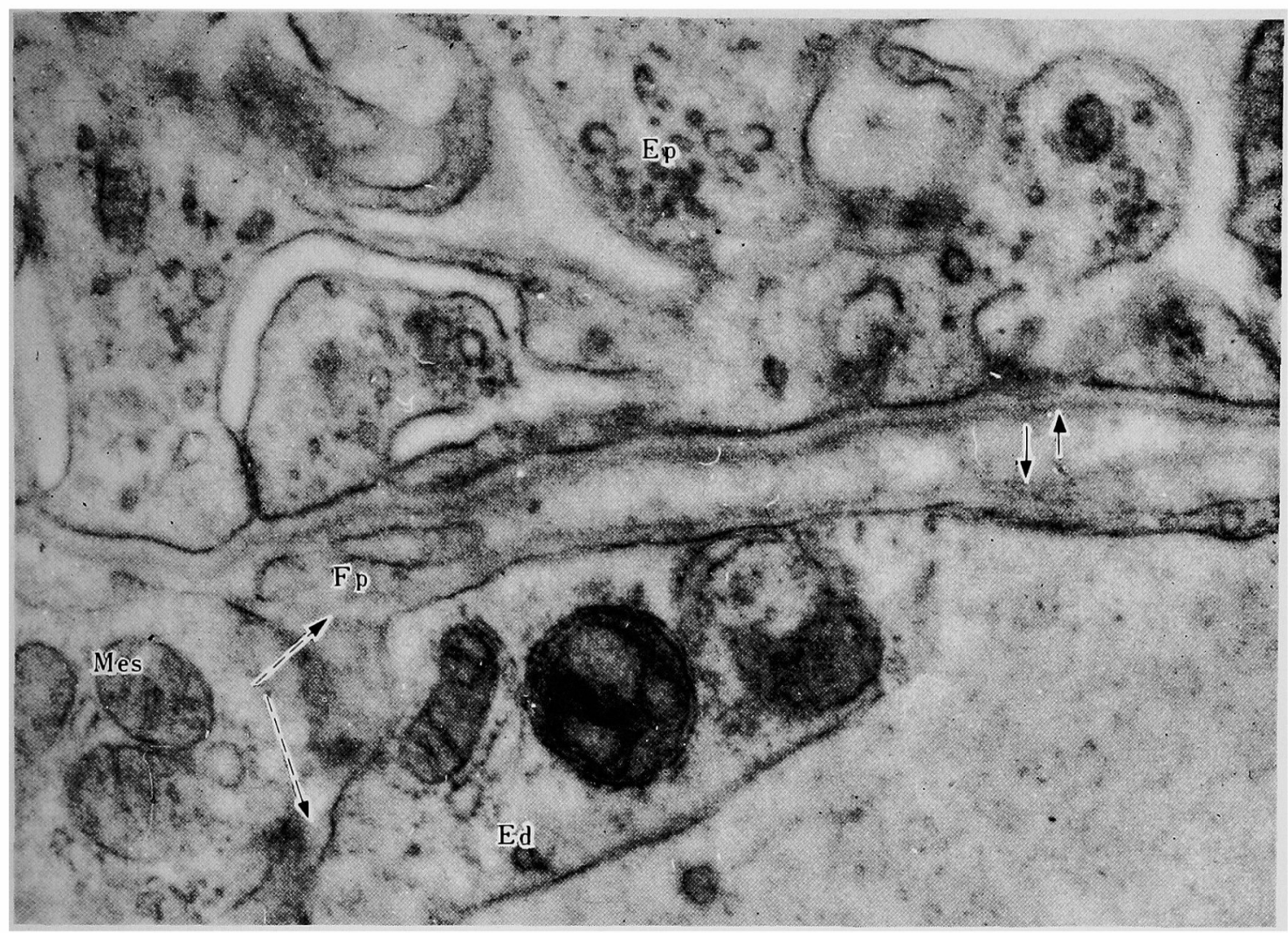

Fig 20

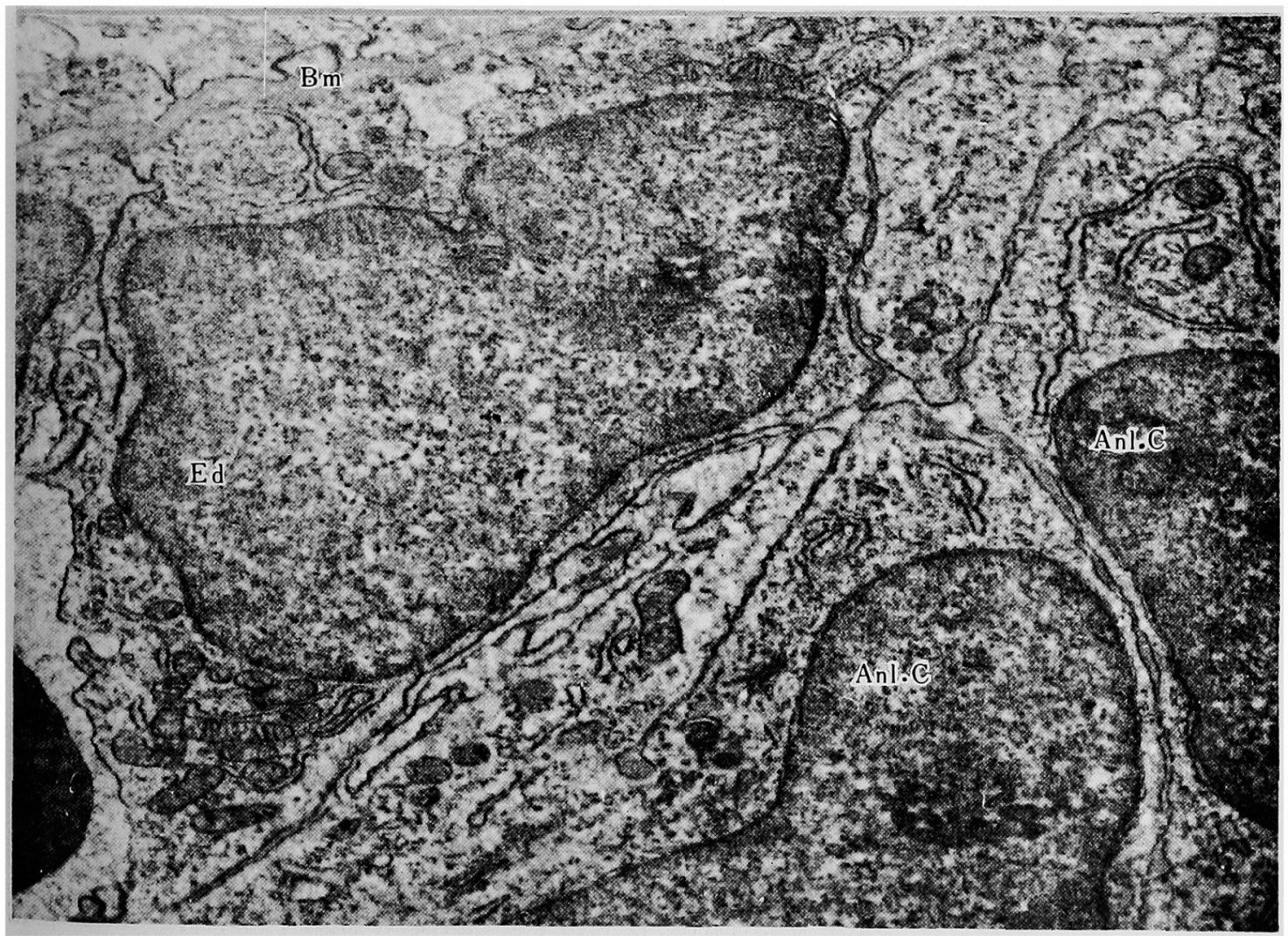




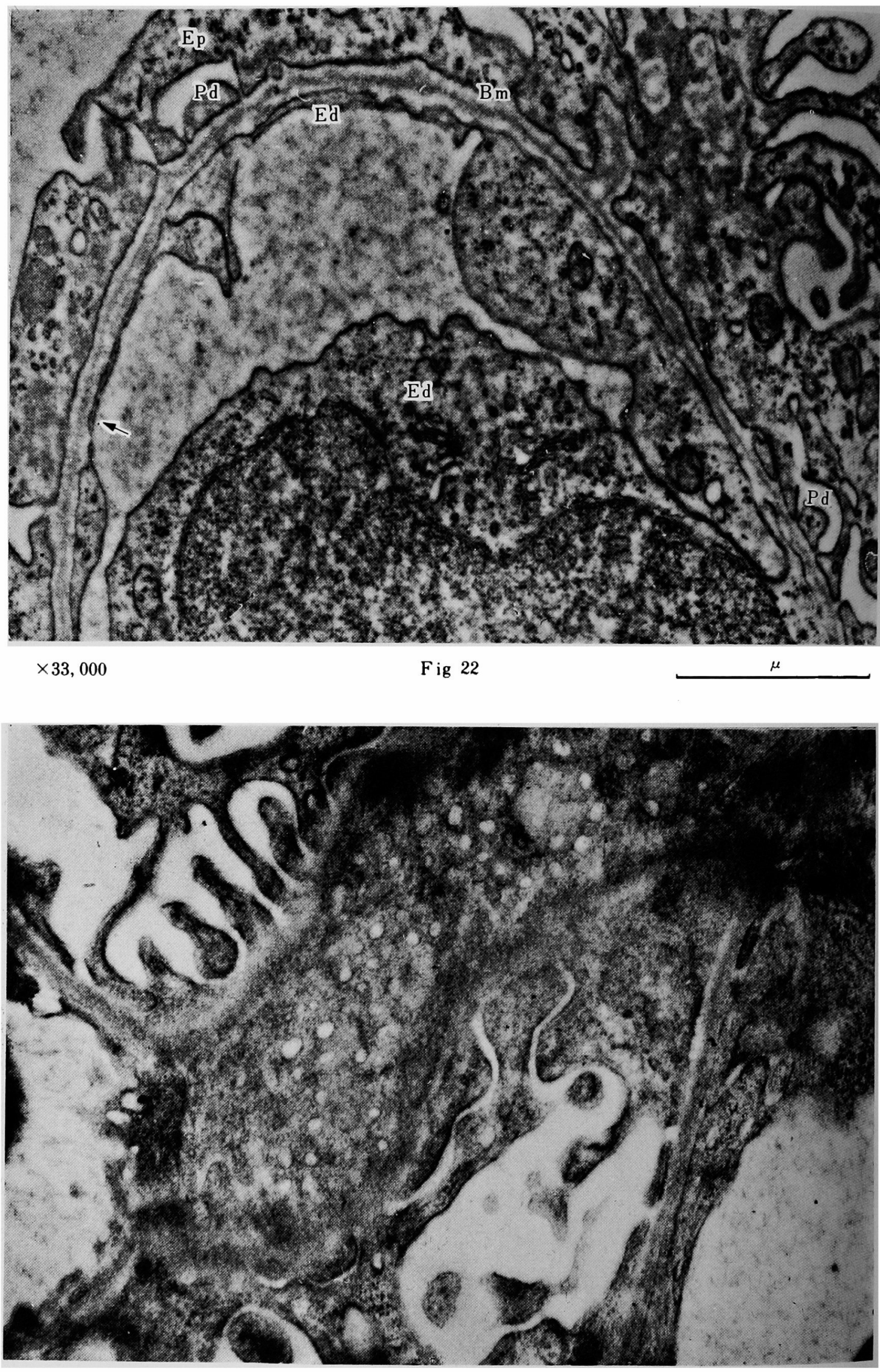



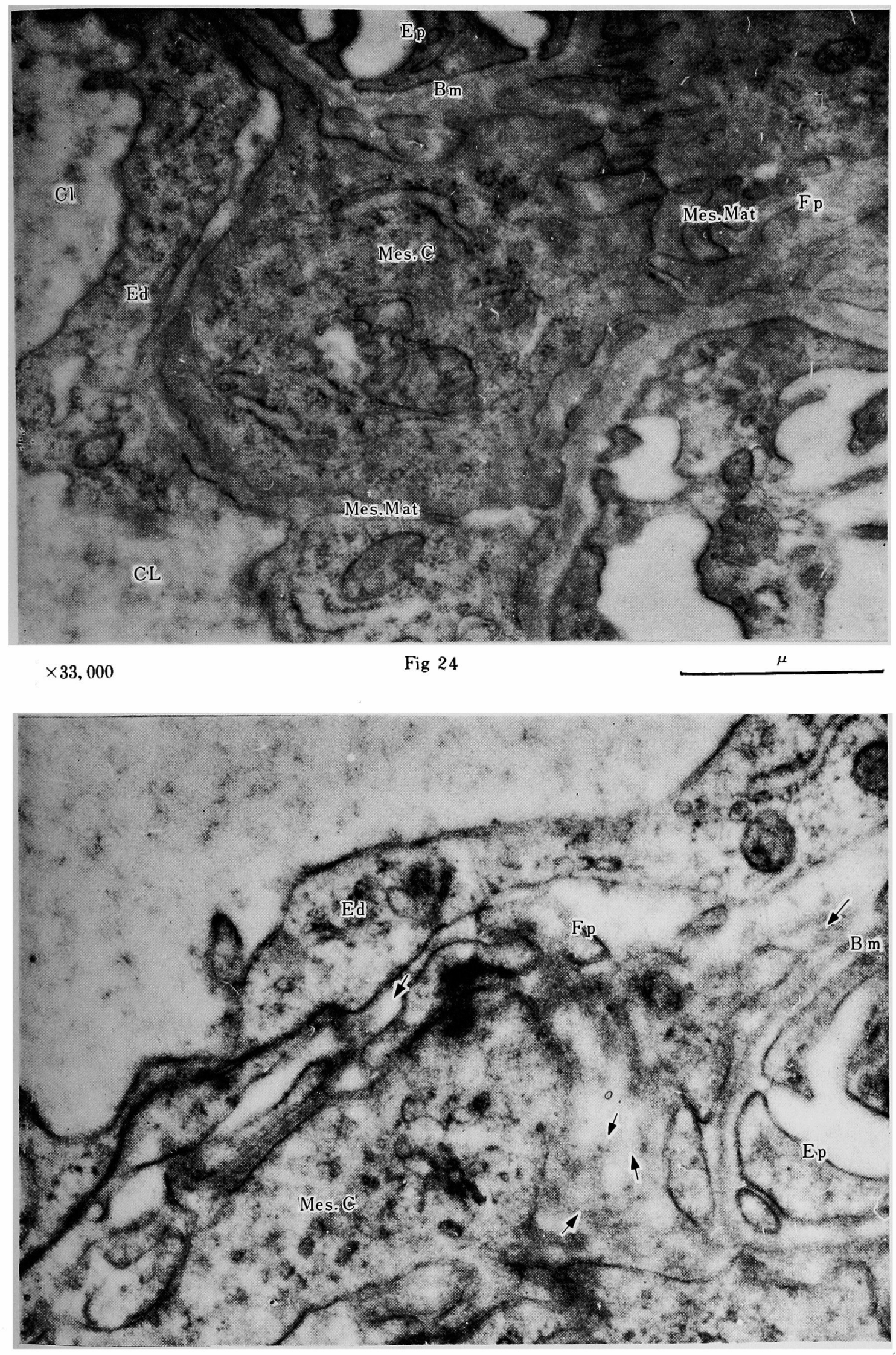